\title{
Mulheres e economia solidária: hora de discutir a relação!
}

\author{
Jussara Carneiro Costa \\ Doutoranda no Programa de Pós-Graduação em Mulheres, Gênero e Feminismos \\ (Universidade Federal da Bahia) \\ Professora na Universidade Estadual da Paraíba \\ juscosta@hotmail.com.
}

\begin{abstract}
Resumo $\mathrm{O}$ surgimento da economia solidária comporta aspectos ainda pouco explorados quanto à presença das mulheres nesse espaço, tais como a crescente e expressiva participação feminina nos grupos que articula, em especial nas organizações políticas que lhe constituem também como movimento social; a participação mais expressiva em grupos mais frágeis e precários; e o fato de serem ocultadas e invisibilizadas tanto no relato acerca das origens e fatos históricos da economia solidária quanto à expressiva participação nos grupos, sem que sejam estabelecidos os parâmetros para analisar as condições de produção dessa ausência. O presente ensaio propõe uma discussão sobre os aspectos problematizados. Para tanto, reconstitui panoramicamente o percurso histórico da economia solidária, suas particularidades na América Latina e Brasil, propondo um diálogo com a teoria de gênero formulada no âmbito feminista, visando reconstituir o percurso das mulheres no campo analisado e problematizar as relações que culminam com sua invisibilização como sujeito. Por último, reflete sobre os significados e reverberações produzidos por tal relação tanto para as trabalhadoras quanto para o movimento social constituído em torno da Economia Solidária.
\end{abstract}

Palavras-chave: mulher; trabalho; relações de gênero; economia solidária; invisibilidade.

\section{Constituindo o panorama de análise: olhares sobre a economia solidária}

A ORIGENS DA ECONOMIA SOLIDÁRIA estão associadas ao surgimento do movimento utópico europeu. ${ }^{1}$ A primeira geração foi formada, inicialmente, por pequenos produtores agrícolas e grupos operários, impulsionados pela necessidade de se organizarem diante da precarização de suas condições de vida (Singer, 2003).

De modo especial na América Latina, a economia solidária, surgida há cerca de trinta anos, restabeleceu o movimento da economia social, iniciado, durante o século XIX, na América do Norte e na Euro-

1 Entre os formuladores das bases para o conceito moderno de utopia são destacados o inglês Thomas More, os socialistas utópicos Saint-Simon, Proudhon, Owen e Fourier, além da crítica de Marx as formulações dos socialistas utópicos. Entre os teóricos contemporâneos que tem estudado o significado sociológico da Economia Solidária, destaca-se a contribuição de Martin Buber, pelo debate conceitual que desenvolve entre socialismo e utopia, analisando criticamente o marxismo ortodoxo, e Boaventura Sousa Santos, com sua crítica ao paradigma moderno e a recolocação da utopia no horizonte das lutas contestatórias. Ver Jandir Pauli (2006). 
pa e depois exportado para os países do Sul. Todavia, se distingue daquele movimento em vários aspectos, particularmente pelo tipo de atores que dele participaram em sua origem. Sua definição se dá, inicialmente, de maneira empírica, a partir da prática dos atores por ela envolvidos. Seus usos são múltiplos, chegando-se a associá-la à economia social, ao terceiro setor, à economia informal, à economia popular e até a entendê-la como novo modo de produção.

Lisboa (2004) realiza uma sistematização interessante para compreender a relação mantida entre essas expressões e a economia solidária. Observa que a categoria economia social surge pela primeira vez na Europa, em 1830, designando uma perspectiva alternativa tanto ao enfoque neoclássico, quanto às correntes institucionalista e marxista, explicitando a afirmação de uma economia imbricada com o social, a recusa do economicismo, a autonomização do econômico face a sociedade, bem como uma forte conotação política, ou seja, expressa um modo de transformação do capitalismo a partir da auto-organização dos produtores e consumidores que se contrapôs à via marxista de tomada do poder estatal.

O uso do termo economia solidária recupera a conotação política inicialmente presente na economia social. É justamente por propor novas alternativas societárias que esta passa a confundir-se com uma ideia de terceiro setor ${ }^{2}$, que sugere um terceiro sistema que tem como principal ator o cidadão, contrastando com o poder acumulado pelo mercado e/ou pelo Estado.

$\mathrm{Na}$ visão de Lisboa (2004), a ideia presente de um terceiro setor expressa uma espécie de vertente privado-empresarial da economia social que, apesar de entrelaçada a esta, distingue-se das vertentes cidadã, cooperativa e estatal, pois a terminologia terceiro setor apresenta caráter mais despolitizado e deriva da literatura norte-americana, na qual se destacam outras expressões como 'organização sem fins lucrativos' e 'organizações voluntárias'.

Com base nisso, ressalta a diferença entre economia solidária e terceiro setor, observando que, embora haja diferentes perspectivas teórico-conceituais sobre esse último, não se pode negar que foi e continua sendo apropriado por uma vertente conservadora, o que retiraria da economia solidária o seu caráter político de movimento crítico da economia capitalista ${ }^{3}$.

Para o autor, é importante observar também que nem todos os empreendimentos da economia solidária são informais ou desvinculados do mercado, mas sua identidade principal reside na sua condição de provedor do sustento do grupo sem a presença da mercantilização do trabalho, com uma racionalidade produtiva fortemente imbricada nas relações sociais de seus membros.

Para Singer (2003), a economia solidária constitui alternativa econômica e social de suplantação do modelo capitalista. $\mathrm{O}$ autor considera que, num primeiro momento, essa aparece como um "híbrido entre o capitalismo e a pequena produção de mercadorias, mas que na realidade se constitui como síntese que supera ambos" (Singer, 2003, p. 13); acredita que a economia solidária tem condições de ampliar a sua condição de economia marginal para, valendo-se dos princípios da autogestão, qualificar-se tecnológica e administrativamente e suplantar o modelo individualista do capitalismo pelos princípios da democracia e da divisão do capital e dos lucros para produção de riquezas. Observando que a exclusão gerada pelo sistema capitalista gera a diminuição do consumo, acredita ser necessário construir um sistema econômico solidário que substitua o princípio da competição pelo da colaboração e do fortalecimento mútuo e que perceba na autogestão a perspectiva da afirmação humana, abandonando os preceitos da exploração do trabalho como condição para tornar viável o sistema econômico.

Singer (2003) endossa a tese de que as crises cíclicas do capitalismo têm origem na redução dos níveis de acumulação do capital que obriga a uma reestruturação modificadora da regulação vigente. Enfatizando a geração de trabalho e emprego como centro da crise, uma vez que os tradicionais acumuladores - o capital, o Estado e os autônomos - entraram em declínio, atribui ao setor autônomo uma espécie de papel 'redentor', por reger-se pela oferta de força de trabalho diante da incapacidade estatal em gerar, por intermédio de investimentos públicos, suficientes postos de trabalho para enfrentar a crise no setor. Para ele, a fragilidade do setor autônomo reside na sua pequenez e no seu isolamento. Como proposta para superar essa fragilidade, propõe a sua abertura para a cooperação e conexões com empreendimentos congêneres para ampliar sua capacidade. Trata-se, portanto, de afirmar a economia solidária como uma experiência de solidariedade entre os autônomos.

Mance (2003) propõe-nos a ideia de uma globalização solidária da economia como alternativa

2 Ricardo Antunes (1999, p. 113), por exemplo, localiza a economia solidária no âmbito do terceiro setor e considera que esta não apresenta potencial para se constituir numa alternativa efetiva e duradoura ao mercado de trabalho capitalista, mas cumpre um papel de funcionalidade ao incorporar parcelas de trabalhadores desempregados pelo capital, considerando "um equivoco concebê-la como uma real alternativa transformadora da lógica do capital e de seu mercado, como capaz de minar os mecanismos da unidade produtiva capitalista".

3 Para Fernandes (1994), na realidade latino-americana a ideia do terceiro setor precisa ser avaliada com outros parâmetros, haja vista muitas iniciativas desenvolvidas nesse âmbito permitirem a ampliação da noção de cidadania e a criação de mecanismos de controle social, redimensionando inclusive o entendimento acerca da "coisa pública". 
pós-capitalista assentada na colaboração solidária e efetivada por meio de redes que conectam empreendimentos de consumo e produção mediante uma reciprocidade de realimentação, contribuindo para a geração de trabalho e renda, fortalecimento do poder local, transformação cultural das comunidades e afirmação da ética solidária.

As redes de colaboração solidária referem-se à relação entre pessoas e empreendimentos como condição de possibilidade de sua viabilidade econômica e social, posto que estabelecem a solidariedade como elemento referencial da articulação. Dessa forma, a perspectiva solidária que funda essas redes é a garantia da circulação de tecnologias, saberes e insumos que permitem não só o reordenamento da cadeia produtiva, mas também a socialização dos acúmulos individuais e coletivos para um projeto alternativo de sociedade.

No Brasil, a exemplo dos demais países da América Latina, a economia solidária é um fenômeno recente. Seu surgimento é comumente associado a três fatores, quais sejam: desemprego estrutural no setor formal/industrial; a ação de movimentos sociais na busca de alternativas solidárias para repensar o mundo do trabalho diante do desemprego estrutural; e dificuldade de movimentos sociais e sindicatos em formular estratégias de enfrentamento do desemprego estrutural, passando a perceber na economia solidária uma ferramenta possível de enfrentamento da organização econômica capitalista. Sua formulação teórica como prática alternativa de geração de trabalho e renda pela incorporação de elementos éticos e políticos aos marcos da economia data do início da década de 1980, quando procurou diferenciar-se do cooperativismo tradicional, inaugurado nas décadas de 1960 e 1970.

A importância alcançada no período pode ser atribuída ao fato de apresentar-se como uma reação contemporânea, uma alternativa possível para os atores sociais, que estão em sua grande maioria excluídos do mercado de trabalho formal e do consumo. Nela, eles se organizam pela via da solidariedade, do trabalho coletivo e do reconhecimento de um ponto em comum, qual seja, a busca do trabalho e renda. De modo geral, pode se dizer que pessoas ou grupos se associam em empreendimentos solidários para compensarem, pela agregação de recursos que cada um dispõe, a ausência de direitos sociais e econômicos provocada pela concentração capitalista e insignificante crescimento econômico, como tem sido observado por Pochmann (2003).
Mais recentes ainda são as políticas públicas criadas para apoiar e fortalecer as ações da economia solidária. No Brasil, foi realizada, em junho de 2003, a I Plenária Nacional da Economia Solidária. $\mathrm{Na}$ ocasião, foi oficializada a criação da Secretaria Nacional de Economia Solidária (SENAES), pelo presidente Luís Inácio Lula da Silva, no âmbito do Ministério do Trabalho e Emprego (MTE). A criação da SENAES é resultado da proposta apresentada ao presidente pelo movimento da sociedade civil, organizado em torno do Grupo de Trabalho da Economia Solidária. Simultaneamente à SENAES, foi criado também o Fórum Brasileiro de Economia Solidária (FBES).

\section{Mulheres, economia solidária e o ato de tornar-se (in)visível}

Um dado que chama a atenção ao se estudar a composição dos grupos articulados em torno da economia solidária tem sido a expressiva participação das mulheres. O Atlas Nacional da Economia Solidária ${ }^{4}$, divulgado pela SENAES em 2007, revelou que, dos 14.954 empreendimentos mapeados, os homens representam $64 \%$ e as mulheres, $36 \%$. Os grupos constituídos somente por mulheres representam $16 \%$ do total, ao passo que os empreendimentos constituídos somente por homens chegam a $11 \%$ e aqueles constituídos por homens e mulheres representam $73 \%$ do total.

Entretanto, os indicadores mais importantes para uma análise das relações de gênero no âmbito da economia solidária referem-se ao tipo de grupo no qual a presença das mulheres predomina: elas são maioria nos empreendimentos menores, compostos por até dez pessoas, já os homens são hegemônicos nos empreendimentos com mais de vinte integrantes.

Os grupos com menor número de integrantes tendem, via de regra, a funcionar na informalidade; acessam poucos recursos, na maioria das vezes do próprio grupo ou de fundos assistenciais de igrejas ou organizações menos restritivas quanto a critérios de viabilidade do investimento e até mesmo ao monitoramento da aplicação. Em boa parte dos casos, as atividades que desenvolvem funcionam como complemento à renda obtida com outras atividades ou por outros membros das famílias. Mesmo assim, conseguem sobreviver às dificuldades, surpreender na capacidade de serem autogestionários e partici- 
par com frequência de organizações políticas como fóruns e redes ${ }^{5}$.

Ainda que se reconheça ser necessária uma investigação mais precisa sobre as razões para a presença das mulheres se mostrar mais expressiva em grupos com tais características, é possível afirmar que há uma relação entre a 'necessidade' que as mulheres enfrentam de conciliar as atividades que desenvolvem nos grupos dos quais participam com as tarefas no âmbito familiar. Afinal, acessar os complexos mecanismos da formalização e gestão econômico-financeira do empreendimento é algo que demanda um tempo do qual ainda não podem dispor. Os arranjos políticos e econômicos tornam-se os possíveis e refletir-se-ão no dos indicadores relativos aos grupos nos quais a presença feminina predomina. As chances de enfrentar as consequências da informalização ficam mais distantes para as mulheres. Se levarmos em consideração o fato de que, de acordo com a legislação brasileira, um grupo para constituir-se como cooperativa - cuja forma jurídica poderia permitir, por exemplo, o acesso a recursos públicos - precisa contar com pelo menos vinte membros, constataremos que, de entrada, boa parte das mulheres já estariam fora dessa possibilidade, fato este que pode vir a se constituir num agravante da situação de precarização já experimentada por aquelas que vivem na informalidade ${ }^{6}$.

Mas essa não é a única exclusão com a qual as mulheres convivem no âmbito da economia solidária. O relato acerca das suas origens históricas as exclui, quando, na verdade, as mulheres jamais estiveram ausentes das primeiras formas de organização. Sobre esse aspecto, Guérin (2003) observa que, na França, por exemplo, com muita frequência, há uma tendência a negligenciar ou, até mesmo, a esquecer o papel decisivo dos grupos de mulheres no movimento associativo francês do século XIX e da primeira metade do século XX.

Para a autora, seja de inspiração laica ou cristã, essas práticas associativas conduzidas por mulheres, que, não raro, visavam "educar" o povo, ou responder de maneira pragmática aos principais problemas enfrentados pelos mais pobres - como tuberculose, a insalubridade das moradias operárias, o analfabetismo -, continham também um verdadeiro projeto coletivo de sociedade. Muitas das experiências inventadas pelas mulheres - a partir do que percebiam como demandas "femininas" - estão na base de profissões relacionadas ao trabalho social - como, por exemplo, educador(a) e assistente social - e na origem das primeiras escolas profissionais e dos centros sociais, inspirando inúmeras reformas sociais francesas.

Ao comentar o esquecimento das mulheres na narrativa acerca das origens históricas da economia solidária, Nobre (2003) observa que a forma como tem sido contada essa história passa a ideia de que as primeiras experiências constituíam assunto exclusivo de homens operários, ideia reforçada pelo mito de que a desestruturação do trabalho masculino e da vida da família trabalhadora se deu pela contratação massiva de mulheres nas fábricas têxteis durante a revolução industrial.

Entretanto, como resgata Scott (1991), as mulheres já trabalhavam muito antes da revolução industrial, como criadas domésticas, empregadas na agricultura, costureiras, chapeleiras, fiandeiras, entre outras profissões. Ainda que não se configurasse como a principal ocupação feminina, o trabalho das mulheres na indústria têxtil foi posto em evidência e tornou-se objeto de um extenso debate, sendo tomado como problema com base no argumento de que as mulheres estariam entrando no terreno dos homens. Mas, se como revela a autora ${ }^{7}$, o trabalho feminino era anterior ao período, por que tanta celeuma a partir de então? Para Scott (1991), havia, na verdade, um grande investimento na construção discursiva de uma divisão sexual do trabalho voltada para a justificação da exploração da mão de obra das mulheres. $\mathrm{O}$ investimento na produção do discurso considerava que o trabalho das mulheres ameaçava a sobrevivência das famílias, não produziu o efeito de retirar-lhes do trabalho na produção, mas a legitimidade para a dupla jornada de trabalho. Em muitas ocasiões, na jornada destinada ao trabalho doméstico, as trabalhadoras ainda encontravam brechas para terminar o trabalho da fábrica, especialmente no acabamento de peças.

Como observa Scott (1991), os empreendimentos que questionavam a lógica capitalista de produção também reproduziam a divisão sexual do trabalho, uma vez que no interior das cooperativas costumava-se adotar legislações protetoras ao trabalho das mulheres que restringiam suas possibilidades de trabalho nas fábricas mas não tocavam nos serviços domésticos, onde estava a maioria das trabalhadoras. Também aí existiam as longas jornadas, o assédio, a violência sexual e más condições de trabalho. Ainda assim, nos espaços de trabalho em regime cooperativo é que conseguiam maior representatividade. Estavam fortemente representadas nas cooperativas de consumo.

5 As afirmações tomam por base dados de campo apurados pela pesquisa Gênero e Economia Solidária: um Encontro Necessário? Interfaces entre a Economia Solidária e o Movimento Feminista na Paraíba, desenvolvida no Programa Institucional de Iniciação Científica da Universidade Estadual da Paraíba, (PROINCVV UEPB) desenvolvida no biênio 2007-2008, sob minha orientação e com a participação da bolsista Jaira Alana Claro Pereira, a época, aluna do curso de Serviço Social da UEPB. Não têm a pretensão de serem conclusivas nem universalizáveis a todos os grupos, mas de indicar uma tendência percebida nos grupos apontados. 6 Embora seja mister salientar as dificuldades encontradas pelos grupos que vêm de uma longa trajetória de informalização, muitas vezes associada a fatores como baixa escolarização, para lidar com o complexo aparato jurídico-legal e o sistema de gestão relacionado a uma cooperativa.

7 Além de apresentar sólidos indicadores referentes à participação das mulheres no mundo do trabalho anteriormente à revolução industrial e em outros setores, a autora apresenta também indicadores relativos a baixa remuneração adquirida pelos homens, impossibilitando-lhes a configuração como único provedor da família operária. 
Pouco a pouco, organizou-se a família operária, constituída pela figura do marido provedor e da esposa dona de casa. Entretanto, como os salários dos trabalhadores eram baixos e grande parte era utilizada na compra de alimentos, no final do século XIX cresceram as cooperativas de consumo de alimentos organizadas por mulheres. As mulheres conseguiam menores preços para os produtos da cesta básica e se organizavam em turnos de trabalho para administrar e fazer funcionar a cooperativa.

Assim, observa-se um forte apelo do movimento cooperativista para o envolvimento permanente das mulheres (em oposição à sua participação temporária no mercado de trabalho), mobilizando-as politicamente de forma intensiva com esta finalidade. Dado o fato de o movimento apoiar o Partido Trabalhista na Inglaterra, as mulheres participantes tornaram-se ativistas de questões como educação, saúde e maternagem (Tilly; Scott apud Nobre, 2003).

Não é difícil entender as razões pela qual se procede ao ocultamento das mulheres como sujeitos da história da economia solidária, posto que por muito tempo estas foram invisibilizadas pelo relato histórico como seres sem história, como observa Perrot (1995). A autora observa que a história das mulheres constitui um empreendimento relativamente novo, revelador de uma profunda transformação: as mulheres como detentoras de uma história, instituídas como agentes históricos, cuja historicidade está relacionada às ações cotidianas e às relações entre os sexos. Trata-se, ainda, de um evento que se traduz numa crítica à própria estrutura de um relato apresentado como universal, não somente para explicitar os vazios e os elos ausentes, mas para sugerir que outra leitura - da história - é possível.

Para Sarda (1987), o tratamento conferido às mulheres pela história carrega as marcas do androcen- trismo presente no discurso lógico-científico, como um dos fatores responsáveis pela instituição da mulher como algo insignificante ${ }^{8}$.

Necessário se faz acrescentar ainda a referência às relações sociais que instituem o androcentrismo como ordenador dessas relações sociais, da própria vida social, invocando, para tanto, a teoria sobre as relações de gênero, que nos permite compreender melhor como se dá a sua articulação com a divisão sexual do trabalho.

As relações de gênero constituem sistemas de poder resultante de um conflito social, que se forma a partir do controle do corpo e da sexualidade da mulher, atuando sobre sua reprodução9. De acordo com Scott (1995, p. 11), "gênero é um forma primeira de significar as relações de poder, ou melhor, é um campo primeiro no seio do qual ou por meio do qual o poder é articulado". Assim, ela nos informa que as mudanças nas relações sociais correspondem sempre à mudança nas representações de poder, sendo que a direção das mudanças não segue sempre um único sentido.

Com base na definição de saber - e sua vinculação com o exercício do poder - desenvolvido por Foucault $(2007)^{10}$, Scott (1994) define o gênero como organização social da diferença sexual, como saber que estabelece significados para as diferenças corporais, que variam de acordo com as culturas, os grupos sociais e o tempo; que indica a diferença sexual como função de nosso saber sobre o corpo, que não pode ser isolado de suas relações numa ampla gama de contextos discursivos.

As implicações políticas do uso da categoria gênero há muito tem constituído uma preocupação para os feminismos (Sardenberg, 2007, Nicholson, 2000, Costa, 2002), tendo em vista que, em certas circunstâncias, a

8 A autora chama a atenção para as diferenças entre androcentrismo e sexismo. Resgatando a etimologia da palavra, sobretudo as qualidades de homem que enseja, dentre as quais se destaca a virilidade, observa que o androcentrismo não se refere a qualquer ser humano do sexo masculino, mas àqueles aos quais se associam um conjunto de valores viris "a uma determinada forma de conceituar o masculino em função da participação no poder bélico, político", sendo composto ainda por um segundo termo, que faz referência a situar-se no centro, gerando uma perspectiva centralista. Considera que o termo sexismo simplifica problemas complexos, posto que as relações sexistas aparecem tanto na vida social quanto nas formulações discursivas que a explicam, nas quais o masculino aparece valorizado como superior e o feminino, como inferior, dependente ou insignificante, sem se precisar exatamente em que condições específicas se produzem essas dessimetrias (Sarda, 1987, p. 22).

9 A teoria de gênero possui vários desdobramentos e não se refere exclusivamente às relações entre homens e mulheres, sobretudo quando se enfatiza a construção discursiva acerca da diferença tendo a sexualidade como referente. Para os objetivos da análise realizada, adotou-se o enfoque baseado nas contribuições de Joan Scott elencadas no trabalho. Para uma análise mais aprofundada, recomenda-se a leitura de Adriana Piscitell, Reflexões em torno de gênero e feminismo (2004), Claudia de Lima Costa, o Tráfego de gênero (1998) e Judith Butler, Problemas de gênero (2003). 10 Como significado de uma compreensão produzida pelas culturas e sociedades sobre as relações humanas, salientando-se sempre o caráter relativo e histórico deste saber, bem como seu caráter político e as relações de poder estabelecidas no seu interior, destacando-se o fato de que o saber não se refere apenas a ideias, mas a instituições, estruturas, práticas cotidianas e rituais específicos; a um modo de ordenar o mundo que não antecede a organização social, mas é inseparável dela. Em As palavras e as coisas, Foucault desenvolverá melhor sua discussão sobre saber, ao formular a noção de episteme, que segundo ele consiste numa elaboração teórica sobre um objeto, segundo uma lógica própria. Assim, as ideias veiculadas por um indivíduo só podem ser captadas quando referidas ao conjunto de pensamentos possíveis a uma época, uma episteme. É a episteme que torna exequível a individualidade a que se dá o nome de autor. Cada período da cultura tem seu a priori histórico, sobre o qual se ergue todo um conjunto de ciências, artes, literaturas, formas de representação que condicionam o pensamento e a atividade dos homens. Posteriormente, na História da sexualidade, com o conceito de dispositivo, vai além da análise que tentava captar as condições de possibilidades históricas de um determinado discurso. 
sua apropriação tem funcionado no sentido de reiterar desvantagens acumuladas pelas mulheres, disfarçada sob a justificativa da inclusão de uma abordagem de gênero ${ }^{11}$. Portanto, a imbricação entre saber e poder trazida pela abordagem de Scott (1994) é fundamental para a análise aqui empreendida, pois torna possível sugerir, com base na contribuição trazida por Sarda (1987), que o androcentrismo apresenta-se como esse saber que, constituído no seio das relações sociais de gênero, opera como um demarcador que institui dinâmicas de poder e não poder para homens e mulheres, impregnando o registro histórico com essa demarcação, espraiando-se pelo tecido que compõe a vida social.

Dessa forma, retorna-se à recomendação de Aguado (2004) de que se discutam os aspectos da vida social marcados pelo androcentrismo, como, por exemplo, o conceito da vida privada, atentando também para a imprescindibilidade da recuperação e reivindicação de temas como significativos para a história social e cultural, a imbricação que apresentam com questões que se vinculam à esfera pública, à política e à economia; as interações entre as diferentes relações de poder, classe e gênero, na conformação das identidades sociais, valorizando como um elemento a mais de análise o papel e a importância que possuem os elementos discursivos e socioculturais nesta conformação, tanto no âmbito público, quanto no âmbito privado.

Tal recomendação permite-nos entender como a própria economia, constituída como campo de saber, ao optar por uma avaliação estritamente mercantil da riqueza e ao se recusar a se imiscuir nas relações familiares, sob o pretexto de respeitar a vida privada, contribui para aprofundar as desigualdades de gênero, não apenas negando a colaboração das mulheres para o bem-estar coletivo, mas, também sacrificando sua liberdade individual em nome de argumentos supostamente científicos e de um objetivo de eficácia coletiva.

Da parte da economia solidária, é curioso observar que ainda que esta anuncie a ruptura com os princípios tradicionais da economia, sobretudo aqueles que concorrem para a sustentação de uma economia nos moldes capitalistas, propondo, no seu lugar, princípios como horizontalidade e solidariedade, a mudança anunciada se torna insustentável quando avaliada segundo o quesito gênero. Revela-se, assim, que a solidariedade anunciada pela economia solidária vincula-se restritamente a uma noção de classe que aparece (des)sexualizada, alheia à interseção mantida com aspectos de gênero, etnorraciais, geracionais, entre outros, e às influências determinantes das relações exercidas no mundo do trabalho. A preocupação com o fim de uma sociedade desigual anunciada pela economia solidária parece não incluir as mulheres.

O próprio Fórum Brasileiro de Economia Solidária constata que não tem havido, ainda, o encontro entre as propostas trazidas pela economia solidária e as reivindicações das mulheres por mais igualdade de direitos e condições no mundo de trabalho.

Ao preparar-se para a IV Plenária Nacional de Economia Solidária, o FBES preparou um caderno para subsidiar os debates. Nele, dedicou uma sessão à relação entre gênero e economia solidária. Logo de início, nesta sessão, reconhece que a Economia Solidária, para efetivar-se como projeto de desenvolvimento, necessita "reconhecer as desigualdades de gênero existentes na base da organização social, econômica, cultural e política da sociedade e, sobretudo, contribuir para sua transformação, construindo a solidariedade de gênero como plataforma da nova sociedade que queremos" (FBES, 2007, p. 65).

O mesmo documento chama a atenção para a necessidade de que a economia solidária reconheça que "as desigualdades de gênero interagem com outras dimensões estruturantes da vida social, que são a classe, a raça e etnia" (FBES, 2007, p. 66) e admite que o debate sobre economia solidária, gênero e mulheres ainda é pequeno e insuficiente diante da grande participação e contribuição feminina às experiências da economia solidária, constatando existir pouca aproximação do movimento da economia solidária com o movimento feminista, e vice-versa, não incorporando, assim, nas suas agendas políticas, temas e questões fundamentais para ambos os movimentos. No mesmo texto, há a sugestão de que a economia solidária assuma a agenda feminista de ruptura com a separação entre produção e reprodução e com a divisão sexual do trabalho.

A constatação dessa ausência tem sido objeto da reivindicação do movimento feminista no âmbito das organizações sociais que integram o campo da economia solidária para que a questão de gênero constitua um dos seus eixos estruturantes, não apenas por considerar a expressividade da participação das mulheres na composição dos empreendimentos que integram a economia solidária, mas, sobretudo, por entender que esta - não esquecendo outras interações - constitui um condicionante para relações de produção e um modelo de sociedade equânime e democrático, tal como reivindicado pela economia solidária (Oliveira, 2005).

Guérin (2003) também compartilha dos aspectos levantados na avaliação da relação entre as mulheres e a eco-

11 Como tem sido frequentemente utilizado por iniciativas desenvolvidas pelo Banco Mundial e instituições do sistema multilateral, sob a alegação de estar se promovendo o desenvolvimento humano das mulheres; por programas governamentais nas diversas esferas de governo; por organizações não governamentais, sindicatos, entre outros. O uso do gênero como um desserviço para as mulheres pode aparecer de várias maneiras. Algumas vezes, como justificativa para liberação do tempo das mulheres para o trabalho, quando na verdade se busca liberá-las para a exploração relacionada a mecanismos trazidos pela reestruturação produtiva; quando se realiza junto à clientela 'mulher' ações que resultam na legitimação de papéis tradicionais que Ihe são atribuídos no âmbito da família, entre outras possibilidades. Basicamente, o que caracteriza essa forma de uso é a não problematização das assimetrias de poder presentes na relação entre mulheres e homens nas ações empreendidas. 
nomia, inclusive a economia solidária. Entretanto, lembra que as transformações ocorridas no interior daquela disciplina - em interação com transformações ocorridas em outras disciplinas - possibilitam visualizar um cenário mais otimista para as mulheres. Para tanto, propõe que num primeiro momento efetue-se a renovação das interpretações ideológicas dos fenômenos ${ }^{12} \mathrm{e}$, num segundo, a identificação e análise das práticas inovadoras e precursoras de transformações sociais importantes, entre as quais inclui a economia solidária, uma vez que

Ao revalorizar as práticas de reciprocidade e de cuidar dos outros não mais enquanto virtudes femininas, mas uma responsabilidade coletiva que contribui para o desenvolvimento pessoal de cada um; ao facilitar a expressão de problemas particulares e a reivindicação de soluções para eles; e, enfim, ao desempenhar um papel de mediação entre diferentes esferas com muita freqüência consideradas compartimentadas, as práticas da economia solidária demonstram que a questão da pobreza feminina e, de maneira mais ampla, a das desigualdades entre homens e mulheres não são uma fatalidade, desde que se admita que dependem de uma responsabilidade compartilhada. (Guérin, 2003, p. 71-72)

Dessa maneira, considera urgente analisar o lugar e o papel das mulheres nesse movimento em plena emergência, as oportunidades e as perspectivas oferecidas, mas também os perigos e os possíveis obstáculos.

\section{Considerações finais}

As ações que vêm sendo desenvolvidas e (re)criadas no âmbito da economia solidária podem se constituir em alternativas para melhorar as condições de trabalho das mulheres que vivem a realidade da informalidade $\mathrm{e}$ precarização, especialmente se considerarmos que a organização a partir de redes de produção, comercialização e acesso a políticas de qualificação profissional e crédito - estratégia bastante utilizada pela economia solidária - pode ajudar a superar o problema do isolamento e fragmentação das trabalhadoras informais, conforme aponta o Atlas Nacional da Economia Solidária.

Para tanto, é preciso que se considere que apenas esta ação não é suficiente para permitir o acesso a direitos negados às trabalhadoras em decorrência da divisão sexual do trabalho e enfrentar a dicotomia produção versus reprodução tão presente no cotidiano delas. Necessário se faz compreender que a presença crescente das mulheres - e de forma mais precária que outros grupos - na economia solidária se dá mediante a difícil conciliação entre vida familiar e vida profissional, tornando-as frequentemente as primeiras a se mobilizarem e a se auto-organizarem, como observa Guérin (2003). Para a autora, esta organização apresenta-se, em primeiro lugar, como um meio de aliviar o cotidiano das mulheres que tropeça em três grandes obstáculos, que são: o caráter multidimensional da pobreza, a inadequação das instituições e a distribuição desigual das obrigações familiares. Assim, a economia solidária necessariamente cria contribuições para supressão desses bloqueios, pois desempenha um papel de justiça de proximidade, e esse papel é essencial diante do caráter multidimensional da pobreza; cria espaços de discussão, reflexão e deliberação coletivas, contribuindo também para redefinir a articulação entre famílias, autoridades públicas, mercado e sociedade; além de proporcionar práticas de reciprocidade entre homens e mulheres, conciliando sua vida familiar e profissional.

Dessa forma, as ações empreendidas pela economia solidária necessitam ter como referência a situação específica dos sujeitos articulados em torno da mesma. Para as mulheres, a identificação das situações por estas vividas, o efeito de tornar visível e dizível os processos de divisão sexual do trabalho ao qual a negatividade dos seus direitos acha-se engendrada é fundamental, lembrando a exortação de Guérin (2003, p. 78) de que "um direito neutro e assexuado pode simplesmente estimular os processos de diferenciação, baseada na desigualdade, em situações em que os comportamentos e estereótipos mantêm as lógicas de dominação".

Talvez uma tarefa para o movimento feminista na interlocução com o movimento da economia solidária seja a de visibilizar e enfatizar a diferença que assinala a condição das mulheres, produzindo, a partir do reconhecimento dessa diferença, uma interação provocadora da remodelagem das organizações aí envolvidas, seja em relação ao direito, seja às normas sociais, no intuito de transformar os sistemas de representação e o imaginário coletivo, por meio das múltiplas organizações sociais, levando os espaços públicos a discutirem e a debaterem problemas que dizem respeito à vida cotidiana, posto que a inadequação das instituições e das normas sociais obstaculiza enormemente a redução das desigualdades que recaem sobre as mulheres.

Desse modo, questões consideradas como não pertinentes à esfera pública e que exercem forte interdição ao exercício de direitos por parte das mulheres, como, por exemplo, as desigualdades intrafamiliares, passam a ser reconhecidas como pertinentes a essa esfera, pois o reconhecimento de que a liberdade feminina tem tanto valor quanto a masculina passa

12 Para o qual sugere três procedimentos, a saber: a construção de indicadores apropriados de avaliação das desigualdades e da pobreza; o reconhecimento da pluralidade das formas de ação e de intercâmbio; o reconhecimento de que a democracia participativa, o debate público e a eficácia econômica são indissociáveis. 
a implicar o reconhecimento de que uma parte das obrigações familiares é um bem público, uma vez que beneficia o conjunto dos contribuintes. Assim, garantir a sobrevivência desse bem público supõe uma redistribuição das responsabilidades entre as famílias, as autoridades públicas, mas também entre o mercado e a sociedade civil (Guérin, 2003).

Para as mulheres, há uma tensão entre o tempo de agir como sujeito político e o de realizar as tarefas para manutenção da vida que deve ser cuidada e reproduzida. A falta de tempo, decorrente de uma dupla jornada de trabalho, dentro e fora de casa, funciona como um bloqueio para transitar da esfera social para a política.
Falta identificar, portanto, como essas questões devem adentrar e integrar os espaços da economia solidária.

Por último, cabe à economia solidária reconhecer que a incorporação das reivindicações feministas - notadamente quanto às interações entre as relações de gênero, étnico-raciais e de geração - constitui condição sine qua non para que esta efetive o status pretendido: de uma economia baseada na solidariedade, construtora de sociabilidades mais solidárias; caso contrário poderá se constituir num campo reprodutor de velhos binarismos, tão vitalizados na economia capitalista (neo)liberal, sobretudo no que se refere à relação produção e reprodução.

\section{Referências}

AGUADO, A. La historia de las mujeres como historia social. In: VALDIVIESO, P. et. al. La historia de las mujeres: uma revisión historiográfica. Vallodolid: Universidad de Vallodolid, 2004. p. 57-.71 .

ANTUNES, Ricardo. Os sentidos do trabalho. 6. ed, São Paulo: Boitempo, 1999.

BRASIL. Secretaria Nacional de Economia Solidária. Disponível em <http://www.mte.gov.br/ecosolidaria/secretaria_nacional.asp>. Acesso em: 06 fev. 2008.

BUTLER, Judith. Problemas de Gênero: feminismo e subversão da identidade. Rio de Janeiro: Civilização Brasileira, 2003.

COSTA, Cláudia Lima. O sujeito no feminismo: revisitando os debates. Cadernos Pagu, n. 19, p. 59-90, 2002.

FERNANDES, Rubem César. Privado porém público: o terceiro setor na América latina. 2. ed. Rio de Janeiro: Relume-Dumará, 1994.

FBES: Fórum Brasileiro de Economia Solidária. Rumo à IV Plenária Nacional de Economia Solidária. Caderno de Aprofundamento aos debates, FBES, nov. 2007.

FOUCAULT, Michel. As palavras e as coisas: uma arqueologia das ciências humanas. 9. ed. São Paulo: Martins Fontes, 2007.

GUÉRIN, Isabelle. Sociologia econômica e relações de gênero. In: EMÍLIO, Marli et al. (Org.). Trabalho e cidadania ativa para as mulheres. Prefeitura Municipal de São Paulo, 2003. p. 71-88.

IBGE. Perfil das mulheres responsáveis pelos domicílios no Brasil. Rio de Janeiro: Ed. do IBGE, 2000.

LISBOA, Armando de Melo. Socioeconomia solidária: marco conceitual latino americano. In: IX ENCONTRO NACIONAL DE ECONOMIA POLÍTICA. Uberlândia, junho 2004. Anais..., 2004. Disponível em: <http://www. sep.org.br>. Acesso em: 14 abr. 2004.

MANCE, Euclides. Redes de colaboração solidária. In: CATTANI, Antônio David (Org.). A outra economia. Porto Alegre: Veraz, 2003.

NICHOLSON, Linda. Interpretando o gênero. Estudos Feministas, v. 8, n. 2, p. 09-41, 2000.
NOBRE, Miriam. As mulheres e a economia solidária. In: CATtANi, D. A. (Org). A outra economia é possível. Porto Alegre: Ed. da UFRGS, 2003. p. 205-211.

OLIVEIRA, Adriana Lucinda. A trajetória de empoderamento das mulheres na economia solidária. Revista Gênero, Niterói, v. 5, n. 2, p.157-177, 2005.

PAULI, Jandir. O poder nas redes de economia solidária. Dissertação (Mestrado) - Porto Alegre, PPGS/UFRGS, 2006. PERROT, M. Escrever uma história das mulhers: relato de uma experiencia. Cadernos Pagu, n. 4, p. 9-28, 1995.

POCHMANN, Marcio. Economia solidária no Brasil: possibilidades e limites. Revista Mercado de Trabalho (IPEA), 2003. Disponível em <http://www.ipea.gov.be>. Acesso em: 12 jan. 2008.

SOUSA SANTOS, Boa Ventura de. Produzir para viver: os caminhos da produção não capitalista. 2. ed. Rio de Janeiro: Civilização Brasileira, 2005.

SARDA, Amparo Moreno. Em torno al androcentrismo en la história. Cuadernos inacabados. El arquétipo viril protagonista de la história. Exercícios de lecturas no andocentricas. Barcelona: La Sal. 1987.

SARDENBERG, Cecília M.B. Back to Women? Translations, Re-significations, and Myths of Gender in Development Planning and Policy in Brazil. In: CORNWALL, WHITEHEAD, A.; E. HARRISON (Org.). Feminisms in development: contradictions, contestations \& challenges. London: Zed Books, 2007. p. 48-64.

SCOTT, Joan Wallach. A mulher trabalhadora. In: FRAISSE, Geneviève; PERROT, Michèle. História das mulheres: o século XIX. São Paulo: Afrontamento, 1991.

SCOTT, Joan Wallach. História das mulheres. In: BURKE, Peter (Org). A escrita da História: novas perspectivas. São Paulo: Edunesp, 1992. p. 63-95.

SCOTT, Joan Wallach. Préfacio a Gender and Polítics of history. Cadernos Pagu, n. 3, Campinas, p. 11-27, 1994.

SCOTH, Joan Wallach. Gênero: uma categoria útil para análise histórica. 2. ed. Recife: SOS Corpo, 1995.

SINGER, Paul. Economia solidária. In: CATTANI, Antônio. A outra economia. Porto Alegre: Veraz, 2003. 


\title{
Women and Solidarity Economy: time to discuss the relationship!
}

\begin{abstract}
The emergence of the social economy includes features not yet explored for the presence of women in space, such as increasing female participation in expressive and articulate groups, particularly in political organizations which are also as a social movement, the most significant participation in groups more fragile and precarious, and the fact that they are both hidden and invisible in reports about the origins and historical facts of the solidarity economy and the significant participation in groups, without the established parameters to analyze the conditions of production of absence. This paper proposes a discussion of the issues debated. To this end, reconstructs the historical landscape of the solidarity economy, its peculiarities in Brazil and Latin America, proposing a dialogue with the theory developed in the context of gender feminist, aiming to reconstruct the path of women in the analyzed field and questioning the relationships that culminate in their invisibility as a subject. Finally, reflect on the meanings and reverberations produced by this relationship both for workers and for the social movement formed around the Solidarity Economy..
\end{abstract}

Keywords: woman; work; gender relations; solidarity economy; invisibility.

\section{Mujeres y Economía Solidaria: jes la hora de discutir la relación!}

\author{
Resumen \\ El surgimiento de la economía solidaria incluye aspectos aún no explorados para detectar la presencia de las mujeres en el espacio, como \\ el aumento y la participación significativa de mujeres en los grupos que se articula, en particular en las organizaciones políticas que \\ están también con la participación del movimiento social más fuerte sobre los grupos más frágiles y precarios, y el hecho que ambos \\ están ocultos e invisibles en la historia de los orígenes y hechos históricos de la economía social com una participación significativa \\ en los grupos, sin imponer cualquier parámetro para analizar las condiciones donde se produce esta ausencia. Este trabajo sugiere una \\ reflexión sobre las cuestiones problematizadas. Para ello, reconstituye el panorama de la ruta histórica de la economía solidaria, sus \\ peculiaridades en Latinoamérica y Brasil, propone un diálogo con la teoría de género formulada en el contexto del feminismo, a fin \\ de reconstruir la trayectoria de la economía solidaria y analizar las relaciones que culminan en su invisibilidad y olvido como sujeto. \\ Por último, reflexiona sobre los significados y las repercusiones producidas por esta relación, tanto para las trabajadoras cuanto para el \\ movimiento social en torno a la Economía Solidaria.
}

Palabras clave: mujer; trabajo; relaciones de género; economía; invisibilidad.

Data de recebimento do artigo: 03-12-2010

Data de aprovação do artigo: 31-01-2011 